\title{
A three dimensional CFD simulation and optimization of direct DME synthesis in a fixed bed reactor
}

\author{
Fazel Moradi ${ }^{1}$, Mohammad Kazemeini ${ }^{1 *}$ and Moslem Fattahi ${ }^{1,2}$ \\ ${ }^{1}$ Department of Chemical and Petroleum Engineering, Sharif University of Technology, Azadi Avenue, P.O. Box 11365- \\ 9465, Tehran, Iran \\ ${ }^{2}$ Department of Chemical Engineering, Abadan Faculty of Petroleum Engineering, Petroleum University of Technology, \\ Abadan, Iran
}

(C) China University of Petroleum (Beijing) and Springer-Verlag Berlin Heidelberg 2014

\begin{abstract}
In this study, a comprehensive three-dimensional dynamic model was developed for simulating the flow behavior and catalytic coupling reactions for direct synthesis of dimethyl ether (DME) from syngas including $\mathrm{CO}_{2}$ in a fixed bed reactor at commercial scale under both adiabatic and isothermal conditions. For this purpose, a computational fluid dynamic (CFD) simulation was carried out through which the standard $k-\varepsilon$ model with $10 \%$ turbulence tolerations was implemented. At first, an adiabatic fixed bed reactor was simulated and the obtained results were compared with those of an equivalent commercial slurry reactor. Then the concentration and temperature profiles along the reactor were predicted. Consequently, the optimum temperature, pressure, hydrogen to carbon monoxide ratio in the feedstock and the reactor height under different operation conditions were determined. Finally, the results obtained from this three-dimensional dynamic model under appropriate industrial boundary conditions were compared with those of others available in literature to verify the model. Next, through changing the boundary conditions, the simulation was performed for an isothermal fixed bed reactor. Furthermore, it was revealed that, under isothermal conditions, the performed equilibrium simulations were done for a single phase system. Considering the simultaneous effects of temperature and pressure, the optimum operation conditions for the isothermal and adiabatic fixed bed reactors were investigated. The results of the $\mathrm{H}_{2}+\mathrm{CO}$ conversions indicated that, under isothermal condition, higher conversion could be achieved, in compared with that under adiabatic conditions. Then, the effects of various operating parameters, including the pressure and temperature, of the reactor on the DME production were examined. Ultimately, the CFD modeling results generated in the present work showed reasonable agreement with previously obtained data available in the literature.
\end{abstract}

Key words: Modeling, CFD, dimethyl ether synthesis, dynamic behavior, fixed-bed reactor, isothermal and adiabatic conditions

\section{Introduction}

Environmental pollution and its prevention are major problems with which people have been concerned for the past several decades. One main source of air pollution is the exhaust gases of automobiles in particular those consuming diesel fuels. Dimethyl ether (DME) might be a very good substitute of such fuels or liquefied petroleum gas (LPG) because it is comparatively clean (Arkharov et al, 2003). DME can be synthesized from syngas, coal or biomass. It has wide ranges of application including LPG substitute, transportation fuel, propellant, chemical feedstock and fuel

*Corresponding author. email: kazemini@sharif.edu

Received May 23, 2013 cell feed ( $\mathrm{Ng}$ et al, 1999). The reaction network involved in a single stage synthesis of DME from syngas is as follows (Papari et al, 2013):

$$
\begin{array}{lr}
\mathrm{CO}+2 \mathrm{H}_{2} \leftrightarrow \mathrm{CH}_{3} \mathrm{OH} & \Delta H=-90.85 \mathrm{~kJ} \cdot \mathrm{mol}^{-1} \\
\mathrm{CO}+\mathrm{H}_{2} \mathrm{O} \leftrightarrow \mathrm{CO}_{2}+\mathrm{H}_{2} & \Delta H=-41.1 \mathrm{~kJ} \cdot \mathrm{mol}^{-1} \\
\mathrm{CO}_{2}+3 \mathrm{H}_{2} \leftrightarrow \mathrm{CH}_{3} \mathrm{OH}+\mathrm{H}_{2} \mathrm{O} & \Delta H=-50.1 \mathrm{~kJ} \cdot \mathrm{mol}^{-1} \\
2 \mathrm{CH}_{3} \mathrm{OH} \leftrightarrow \mathrm{CH}_{3} \mathrm{OCH}_{3}+\mathrm{H}_{2} \mathrm{O} & \Delta H=-23.4 \mathrm{~kJ} \cdot \mathrm{mol}^{-1}
\end{array}
$$

In previous work by our research group, it is shown that the above four reactions are not independent on each other, but one might be obtained from the combination of the remaining three (Papari et al, 2012). In the present 
work; reactions 1, 3 and 4 are considered and treated as the independent ones and designated as reactions $\mathrm{A}, \mathrm{C}$ and $\mathrm{DME}$ (i.e., $r_{\mathrm{A}}, r_{\mathrm{C}}$ and $\left.r_{\mathrm{DME}}\right)$. A chemical route called synthesis gas to DME (STD) process for direct synthesis of DME (from synthesis gas) in a single reactor over a bi-functional catalyst was developed. The most common bi-functional catalysts reported in literature for the STD process are physical mixtures of materials containing those of the methanol synthesis catalyst as well as solid acid catalyst for methanol dehydration to DME (Khandan et al, 2008). Amongst the solid acid catalysts used for methanol dehydration, ZSM-5 and $\gamma-\mathrm{Al}_{2} \mathrm{O}_{3}$ are the two materials studied intensively both for academic and commercial purposes (Alamolhoda et al, 2012). Topsoe has developed such bi-functional catalyst through addition of $\mathrm{H}-\mathrm{ZSM}-5$ to traditional $\mathrm{CuO} / \mathrm{ZnO} / \mathrm{Al}_{2} \mathrm{O}_{3}$ methanol synthesis catalyst (Topsoe, 1993a, 1993b). H-ZSM-5 is the best dehydration catalyst in the STD process because of its larger number of Brønsted acid sites with moderate acid strength (Takeguchi et al, 2000; Yaripour et al, 2005; Moradi et al, 2007). In this process a fixed-bed reactor is utilized and reaction takes place in a series of reactors operating adiabatically with inter-stage coolers. Adiabatic reactors are preferred because of their simple design and easy operation; however, for highly exothermic reactions the temperature rise might be unacceptable. Jahanmiri and Eslamloueyan (2002) have simulated the fixed-bed reactor for methanol synthesis as heterogeneous 1-D and 2-D systems. Shahrokhi and Baghmisheh (2005) have simulated the dynamic behavior of a fixed-bed reactor for methanol production and proposed an optimization based upon maximizing the production rate. A pilot scale plant (5 tons/day) ran successfully in 1999 under the support of the Japanese government, and a 100 tons/day commercial plant was built in Hokkaido, Japan (Ogawa et al,
1999). However, the simulation and design of industrial DME synthesis reactors is rarely reported.

In the present work, a simulation of the DME production over the $\mathrm{Cu} / \mathrm{ZnO} / \mathrm{Al}_{2} \mathrm{O}_{3} / \mathrm{ZrO}_{2}$ catalyst was investigated. A computational fluid dynamic (CFD) dynamic simulation in three dimensions was developed for adiabatic and isothermal fixed bed reactors. The results obtained were compared with those available in the literature, and the reasonable agreement showed the validity of this model. Moreover, the concentration and temperature profiles along the reactor were obtained and the optimum operation conditions were determined.

\section{Reaction kinetics}

A kinetic model for methanol synthesis and DME production over $\mathrm{Cu} / \mathrm{ZnO} / \mathrm{Al}_{2} \mathrm{O}_{3} / \mathrm{ZrO}_{2}$ catalyst was selected to evaluate the effect of carbon dioxide on the reaction rates due to the high activity and stability of $\mathrm{CO}_{2}$. In this kinetic model three independent reactions were considered (i.e.; Reactions 1, 3 and 4). There existed six components in this kinetic scheme including $\mathrm{H}_{2}, \mathrm{CO}, \mathrm{CO}_{2}, \mathrm{H}_{2} \mathrm{O}$, methanol and DME. The first three $\left(\mathrm{H}_{2}, \mathrm{CO}, \mathrm{CO}_{2}\right)$ were the main reactants. The inclusion of the inert components such as $\mathrm{N}_{2}$ and $\mathrm{CH}_{4}$ was necessary to absorb the heat of reaction and control the reactor pressure (Yasari et al, 2010). The reaction was assumed to be reversible since the concentration of methanol was high, and the Langmuir-Hinshelwood model was applied for the reaction rates. The assumption of a rapid equilibrium was applied to the adsorption steps, and the rates were developed when a particular reaction was assumed to be a rate determining step (RDS). For this purpose, reaction rates for particular RDS available in literature (presented in Table 1) were utilized.

Table 1 Rates for the reactions in this work (Lim et al, 2009)

\begin{tabular}{|c|c|}
\hline RDS & Rate \\
\hline $\begin{array}{l}r_{\mathrm{A}}(\mathrm{CO} \text { hydrogenation }) \\
\quad(\text { Reaction No. 1) }\end{array}$ & $r_{\mathrm{A}}=\frac{k_{\mathrm{A}} K_{\mathrm{CO}} K_{\mathrm{H}_{2}}{ }^{0.5}\left(P_{\mathrm{CO}} P_{\mathrm{H}_{2}}^{2}-\frac{P_{\mathrm{CH}_{3} \mathrm{OH}}}{K_{P A}}\right) / P_{\mathrm{H}_{2}}{ }^{1.5}}{\left(1+K_{\mathrm{CO}} P_{\mathrm{CO}}\right)\left(1+K_{\mathrm{H}_{2}}{ }^{0.5} P_{\mathrm{H}_{2}}^{0.5}+K_{\mathrm{H}_{2} \mathrm{O}} P_{\mathrm{H}_{2} \mathrm{O}}\right)}$ \\
\hline $\begin{array}{c}r_{\mathrm{C}}\left(\mathrm{CO}_{2} \text { hydrogenation) }\right. \\
\quad \text { (Reaction No. 3) }\end{array}$ & $r_{\mathrm{C}}=\frac{k_{\mathrm{C}} K_{\mathrm{CO}_{2}} K_{\mathrm{H}_{2}}^{0.5}\left(P_{\mathrm{CO}_{2}} P_{\mathrm{H}_{2}}^{3}-\frac{P_{\mathrm{CH}_{3} \mathrm{OH}} P_{\mathrm{H}_{2} \mathrm{O}}}{K_{P C}}\right) / P_{\mathrm{H}_{2}}^{2.5}}{\left(1+K_{\mathrm{CO}_{2}} P_{\mathrm{CO}_{2}}\right)\left(1+K_{\mathrm{H}_{2}}^{0.5} P_{\mathrm{H}_{2}}^{0.5}+K_{\mathrm{H}_{2} \mathrm{O}} P_{\mathrm{H}_{2} \mathrm{O}}\right)}$ \\
\hline $\begin{array}{l}r_{\mathrm{DME}}(\text { DME production) } \\
\quad \text { (Reaction No. 4) }\end{array}$ & $r_{\mathrm{DME}}=\frac{k_{\mathrm{DME}} K_{\mathrm{CH}_{3} \mathrm{OH}}{ }^{2}\left(C_{\mathrm{CH}_{3} \mathrm{OH}}{ }^{2}-\frac{C_{\mathrm{DME}} C_{\mathrm{H}_{2} \mathrm{O}}}{K_{P, D M E}}\right)}{\left(1+2\left(K_{\mathrm{CH}_{3} \mathrm{OH}} C_{\mathrm{CH}_{3} \mathrm{OH}}\right)^{0.5}+K_{\mathrm{H}_{2} \mathrm{O}} C_{\mathrm{H}_{2} \mathrm{O}}\right)^{4}}$ \\
\hline
\end{tabular}

Due to the nonlinearity of these reaction rates, they were defined in the ANSYS FLUENT through writing a user defined function (UDF). The temperature dependency of kinetic parameters pointed to a strong nonlinearity of reaction rate constants in turn, resulting in the following Arrhenius forms (Lim et al, 2009):

$$
k_{\mathrm{i}}(T)=k_{\mathrm{i} 0} \exp \left[-\frac{E_{\mathrm{i}}}{R}\left(\frac{1}{T}-\frac{1}{T_{0}}\right)\right]
$$




$$
K_{\mathrm{i}}(T)=K_{\mathrm{i} 0} \exp \left[-\frac{\Delta H_{\mathrm{i}}}{R}\left(\frac{1}{T}-\frac{1}{T_{0}}\right)\right]
$$

Equilibrium constants, $K_{\mathrm{PA}}, K_{\mathrm{PB}}$, and $K_{\mathrm{PC}}$ are for $\mathrm{CO}$ hydrogenation (A), the water gas shift (WGS) (B) and $\mathrm{CO}_{2}$ hydrogenation (C) reactions, respectively, and determined through fitting the available experimental data from literature (Lim et al, 2009). Moreover, the equilibrium constant for the DME production was taken from the literature (Lim et al, 2009). The overall reaction rate constants are summarized in Table 2. A detailed kinetic mechanism on the basis of different sites on $\mathrm{Cu}$ for the adsorption of carbon monoxide and carbon dioxide was applied through the selected model. The kinetic model included the WGS reaction in order to provide a relationship between the hydrogenations of carbon monoxide and carbon dioxide.

Table 2 Kinetic constants and reaction rates utilized in work (from Lim et al, 2009)

\begin{tabular}{|c|c|}
\hline $\ln K_{\mathrm{PA}}=\frac{9.8438 \times 10^{4}}{R T}-29.07$ & $k_{\mathrm{A}}=1.16 \times 10^{-9} \exp \left[-\frac{7.01 \times 10^{3}}{R}\left(\frac{1}{T}-\frac{1}{523}\right)\right]$ \\
\hline $\ln K_{\mathrm{PB}}=-\frac{4.3939 \times 10^{4}}{R T}+5.639$ & $k_{\mathrm{B}}=2.82 \times 10^{-5} \exp \left[-\frac{2.70 \times 10^{2}}{R}\left(\frac{1}{T}-\frac{1}{523}\right)\right]$ \\
\hline$K_{\mathrm{PC}}=K_{\mathrm{PA}} \times K_{\mathrm{PB}}$ & $k_{\mathrm{C}}=1.15 \times 10^{-6} \exp \left[-\frac{1.19 \times 10^{2}}{R}\left(\frac{1}{T}-\frac{1}{523}\right)\right]$ \\
\hline$K_{\mathrm{DME}}=0.106 \exp \left[\frac{2.1858 \times 10^{4}}{R T}\right]$ & $k_{\mathrm{DME}}=2.51 \times 10^{11} \exp \left[-\frac{6.45 \times 10^{5}}{R}\left(\frac{1}{T}-\frac{1}{523}\right)\right.$ \\
\hline$K_{\mathrm{CO}}=4.96 \times 10^{-8} \exp \left[\frac{9.93 \times 10^{3}}{R}\left(\frac{1}{T}-\frac{1}{523}\right)\right]$ & $K_{\mathrm{CH}_{3} \mathrm{OH}}=1.41 \times 10^{-3} \exp \left[\frac{6.05 \times 10^{3}}{R}\left(\frac{1}{T}-\frac{1}{523}\right)\right.$ \\
\hline$K_{\mathrm{CO}_{2}}=1.858 \times 10^{-6} \exp \left[\frac{5.3795 \times 10^{4}}{R T}\right]$ & $K_{\mathrm{H}_{2} \mathrm{O}}=0.84 \times 10^{-1} \exp \left[\frac{4.11 \times 10^{4}}{R T}\right]$ \\
\hline$K_{\mathrm{H}_{2}}=0.6716 \exp$ & $\left.-\frac{6.476 \times 10^{3}}{R T}\right]$ \\
\hline
\end{tabular}

\section{Reactor simulations}

Computational fluid dynamic theory is a comprehensive method for evaluating and predicting the performance of systems involving fluid flow, energy transfer and related phenomena. Such calculations are usually achieved by computer simulations. CFD codes solve the mass/continuity, momentum and energy equations on a domain determined by the user. The 3-D geometry of a reactor with a diameter of 7 $\mathrm{m}$ and a height of $50 \mathrm{~m}$ was created in the present simulation. An irregular mesh size selected by using the commercial grid-generation tool of the GAMBIT software (FLUENT Inc.) with the Tet/Hybrid elements and TGrid types which were compatible with one other contained 1,731,560 cells totally. Moreover, due to the cylindrical geometry utilized, in some places the elements were hexagonal, pyramidal and quadrilateral, hence, refined meshing was necessary near the wall. The projection of the grid on a vertical plane $(y, z)$ is shown in Fig. 1.

The numerical simulation was carried out using a commercial CFD package ANSYS FLUENT based on the finite-volume methods. Furthermore, a three dimensional
(3-D) heterogeneous dynamic model was used to simulate the reactor. The assumptions implemented in the present simulation are summarized as follows:

-Catalyst deactivation was not considered.

-Steady state was applicable.

-Simulations were conducted utilizing ideal gas law, which was also applied in a previous study (Papari et al, 2012).

-Pressure based module was chosen for the solver.

-The $k-\varepsilon$ model for turbulence was applied.

-Specific thermal capacity was defined using a mixing law.

-Thermal conductivity and viscosity were defined by the ideal mixing law and

-Mass diffusion parameters and thermal diffusion coefficient were defined by the kinetic theory.

Moreover, a second order discretization scheme (QUICK: Quadratic Upwind Interpolation for Convective Kinematics) was chosen for the turbulent dissipation rate and void fraction equations in order to limit their numerical dispersion (e.g., calculation errors due to grids and discretization schemes). A first order discretization scheme was tested for the solution of 


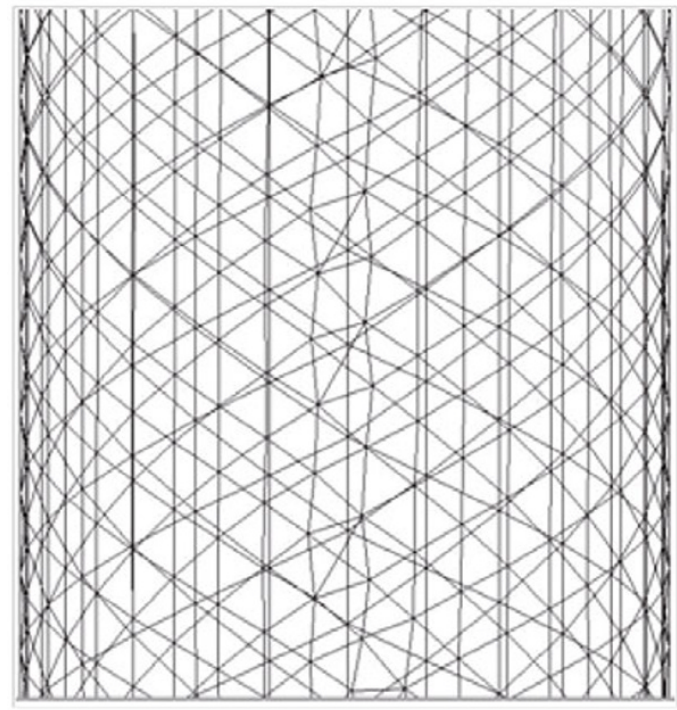

Fig. 1 The projection of the grid on a vertical plane $(y, z)$ determined in this work

the momentum equations; however, it led to unstable results. Then, a second order discretization scheme (QUICK) was utilized to solve all the equations. The SIMPLE (Semi-Implicit Method for Pressure-Linked Equations) pressure-velocity coupling scheme was also used. The governing equations for the fluid flow in the catalytic bed were the transport equations for each species, as well as the continuity, momentum and energy equations for the feed gas mixture.

\subsection{Continuity equation}

Conservation of mass or continuity equation is expressed as follows:

$$
\frac{\partial \rho}{\partial t}+\frac{\partial\left(\rho u_{i}\right)}{\partial x_{i}}=S_{m}
$$

In this equation $S_{m}$ contains the mass added through phase changes or user defined sources. In general, and in the simulations described here, the source term was equal to zero.

\subsection{Momentum equation}

Navier-Stokes equations were utilized for description of the momentum changes. The equation for conservation of momentum in the ith direction is defined by:

$$
\frac{\partial\left(\rho u_{i}\right)}{\partial t}+\frac{\partial\left(\rho u_{i} u_{j}\right)}{\partial x_{j}}=-\frac{\partial p}{\partial x_{i}}+\frac{\partial \tau_{i j}}{\partial x_{j}}+\rho g_{i}
$$

where $\rho g_{i}$ is the gravitational body force and $\tau_{i j}$ is the stress tensor. The stress tensor for a Newtonian fluid is defined by:

$$
\tau_{i j}=\left[\mu\left(\frac{\partial u_{i}}{\partial x_{j}}+\frac{\partial u_{j}}{\partial x_{i}}\right)\right]-\frac{2}{3} \mu \frac{\partial u_{i}}{\partial x_{i}} \delta_{i j}
$$

where $\delta_{i j}$ is the Kronecker delta function.

\subsection{Energy equation}

The energy equation was solved in the form of the transport equation for a static temperature. The energy equation is obtained from the enthalpy balance taking the temperature as a dependent variable. The enthalpy equation balance is defined as:

$$
\frac{\partial(\rho h)}{\partial t}+\frac{\partial\left(\rho u_{i} h\right)}{\partial x_{i}}=\frac{\partial\left(k_{f} \frac{\partial T}{\partial x_{i}}-\sum_{j} h_{i} J_{i j}\right)}{\partial x_{i}}+u_{i} \frac{\partial p}{\partial x_{i}}+S_{h}
$$

In this equation $S_{h}$ includes the heat of chemical reaction, any inter-phase exchange of heat and any other user-defined volumetric heat sources.

\subsection{Species transport equation}

The local mass fraction of each species is predicted by using the solution of a convection-diffusion equation. The species transport equation takes the following general form:

$$
\frac{\partial\left(\rho Y_{i}\right)}{\partial t}+\frac{\partial\left(\rho u_{i} Y_{i}\right)}{\partial x_{i}}=-\frac{\partial J_{i j}}{\partial x_{i}}+R_{i}
$$

where $J_{i j}$ is the diffusion flux of species $i$ in the $j$ th direction and $R_{i}$ is the net rate of production of species $i$ by the chemical reaction. The diffusion flux of species is calculated based on the Stefan-Maxwell equations. Moreover, the kinetic theory applied for description of mass diffusion coefficient is calculated from modification of the Chapman-Enskog formula:

$$
D_{i j}=0.00188 \frac{\left[T^{3}\left(\frac{1}{M_{w, i}}+\frac{1}{M_{w, j}}\right)\right]^{1 / 2}}{P_{a b s} \sigma_{i j}{ }^{2} \Omega_{D}}
$$

where $P_{a b s}$ is the absolute pressure, $\sigma$ is the Lennard-Jones' characteristic length and $\Omega_{D}$ is the diffusion collision integral, a measure of the molecular interactions in the system.

The value $10^{-6}$ was set for checking the convergence criteria of the solution. All the simulations were carried out by a workstation equipped with two Intel Xeon $3.0 \mathrm{~Hz}$ processors, 16GB RAM, using the parallel processing module in FLUENT. Gas flow entered at the bottom of the reactor, and the mass flow inlet boundary condition was selected as the input boundary condition. For the exhaust gas from the top of the column, a pressure outlet boundary condition with a zero value of relative static pressure was considered. Other boundaries of the reactor were defined with wall type through which the slip boundary condition was ignored. The wall type was first applied under the adiabatic condition then changed to the isothermal condition. For both these conditions, the porous zone of the catalytic reactor was accounted for all cell regions.

\section{Results and discussion}

The parameters used in simulation are provided in Table 3. The mesh independency is displayed in Fig. 2. The result of this simulation is compared with those of Papari et al, 2012 and shown in Fig. 3. Papari and co-workers modelled a slurry bed reactor with the same dimensions as that of the present fixed bed reactor under the same operating conditions. 
Table 3 Operational parameters utilized in the present simulation

\begin{tabular}{lc}
\hline \multicolumn{1}{c}{ Parameters } & Value \\
\hline Temperature, ${ }^{\circ} \mathrm{C}$ & 260 \\
Pressure, $\mathrm{MPa}$ & 5.0 \\
Superficial gas velocity, $\mathrm{m} / \mathrm{s}$ & 0.2 \\
Reactor diameter, $\mathrm{m}$ & 7 \\
Reactor height, $\mathrm{m}$ & 50 \\
W/F: Catalyst weight $(\mathrm{W})$ over flow rate $(\mathrm{F}), \mathrm{g}_{\text {cat }} \cdot \mathrm{h} / \mathrm{mol}$ & 5 \\
\hline
\end{tabular}

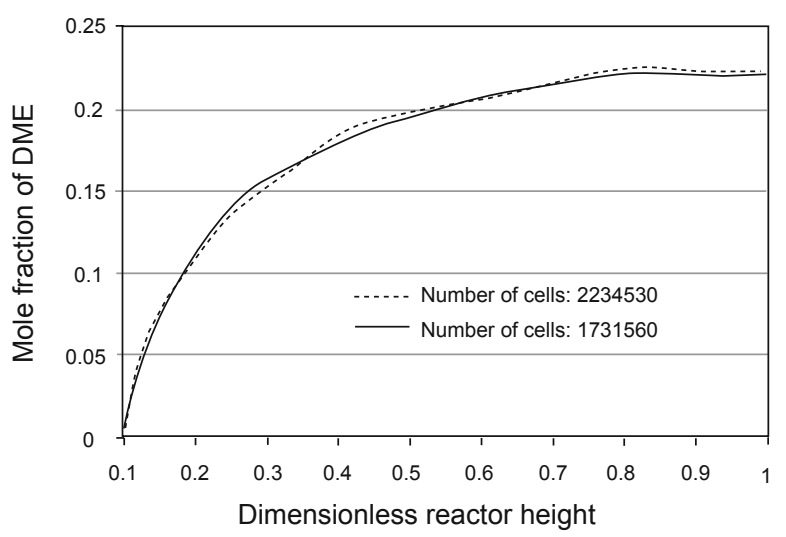

Fig. 2 Mesh-independency of the reactor simulation

It is reiterated that, due to the large dimensions of the considered reactor, it is reasonable to conclude these results were rather close to one another in terms of the behavioral patterns obtained. Moreover, the mass transfer resistance can be ignored due to the high residence time. The effect of the pressure variation on the mole fractions of carbon monoxide and DME is demonstrated in Fig. 4. According to the equation (1) and by considering Le Chatelier's principle (Farsi and Jahanmiri, 2011), by increasing the pressure more carbon monoxide might be converted. However, a pressure above 5.0 MPa will lead to a decrease in the amount of the produced DME. Thus, the optimum pressure for this reactor is determined to be $5.0 \mathrm{MPa}$. Under the operating conditions in Table 3 and using this optimum pressure (5.0 MPa), the mole fractions of the DME and methanol versus the height of the reactor at three temperatures of 260,270 and $280{ }^{\circ} \mathrm{C}$ are presented in Fig. 5. When the inlet temperature of the feed increased from 260 to $270{ }^{\circ} \mathrm{C}$, the production of methanol decreased while that of the DME increased. On the other hand, the corresponding optimum height of the reactor needed (i.e.; the height where methanol synthesis stopped) shown in Fig. 6 increased from 42 to $46 \mathrm{~m}$ when the inlet temperature of the feed increased from 260 to $270{ }^{\circ} \mathrm{C}$. Further temperature enhancement above $270{ }^{\circ} \mathrm{C}$ due to the exothermic nature of the reactions involved, caused more methanol and carbon monoxide to be removed from the reactor as unreacted materials, hence, the production of DME decreased. Under this condition, the optimum height of the reactor needed increased to $48 \mathrm{~m}$.

In order to optimize the temperature and pressure
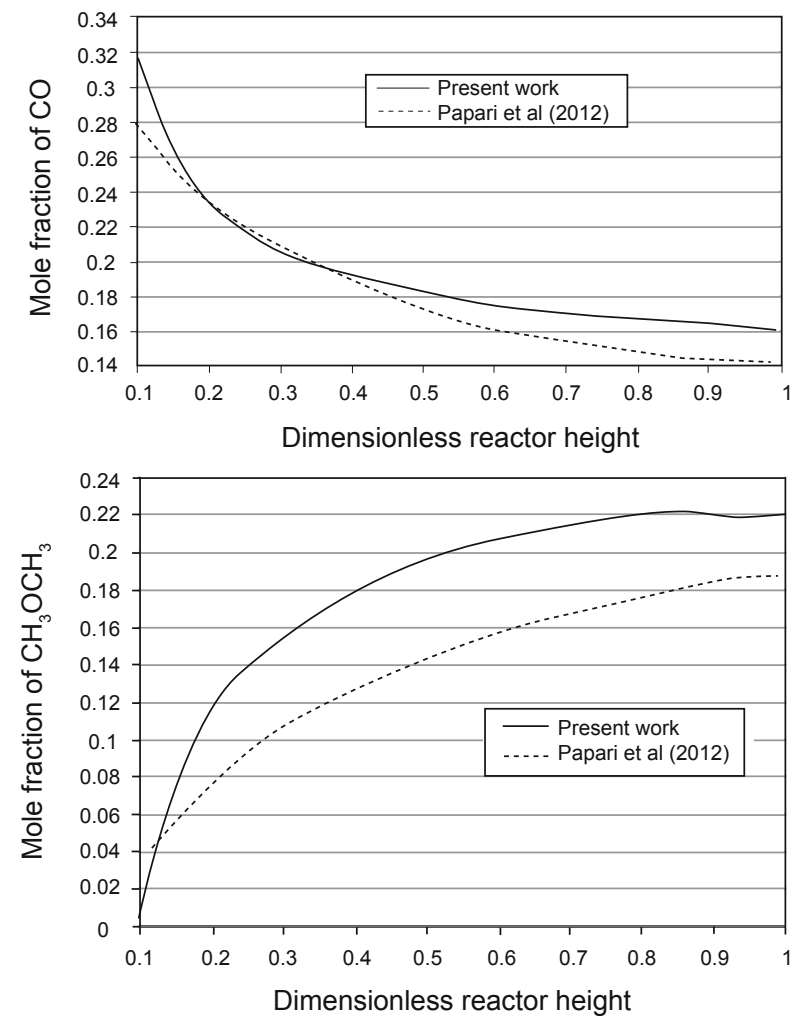

Fig. 3 Variation of $\mathrm{CO}$ and DME mole fractions along the reactor height
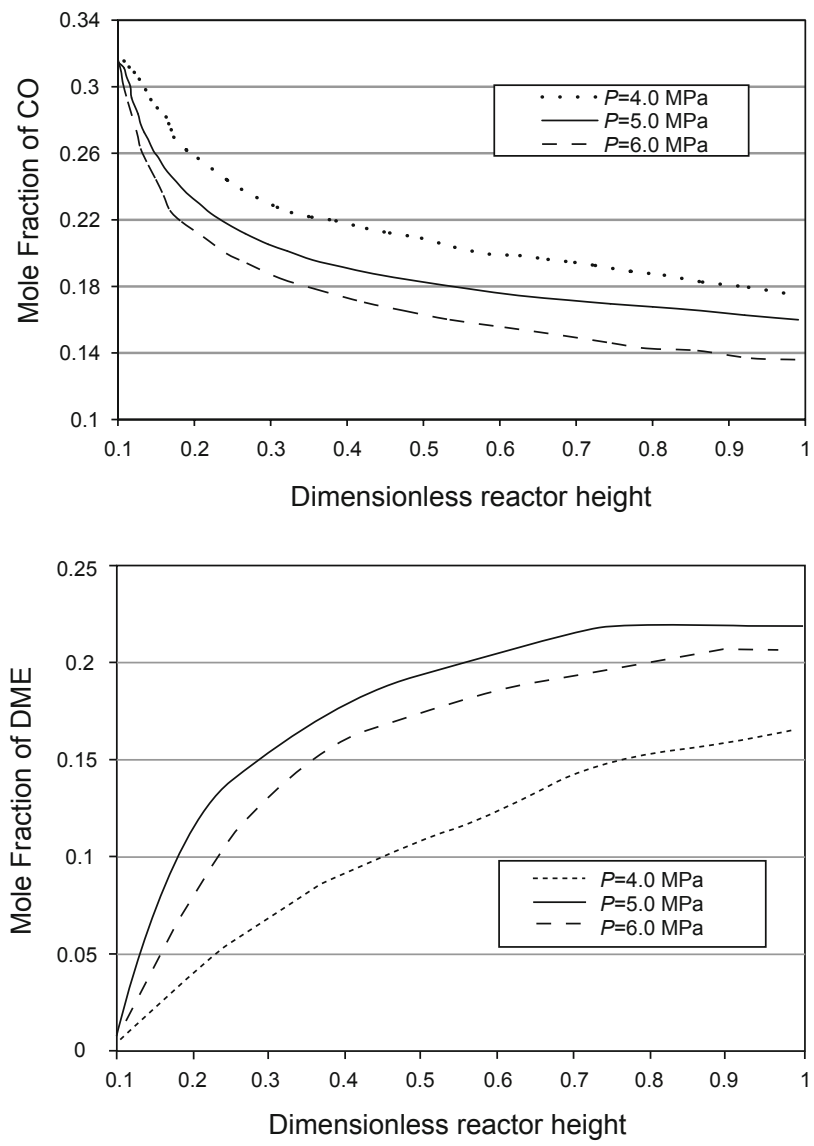

Fig. 4 Effect of pressure on mole fractions of carbon monoxide and DME along the reactor height 
simultaneously, the selectivity for DME production and the conversion of $\mathrm{H}_{2}+\mathrm{CO}$ are represented in Fig. 7. The conversion of $\mathrm{H}_{2}$ and $\mathrm{CO}$, as well as the DME selectivity formula is provided in Appendix A.

Fig. 7 shows that the best selectivity for the DME synthesis at the three pressures $(4.0,5.0$ and $6.0 \mathrm{MPa})$ was obtained at $270{ }^{\circ} \mathrm{C}$. Furthermore, at $270{ }^{\circ} \mathrm{C}$ and $5.0 \mathrm{MPa}$, the conversion of $\mathrm{H}_{2}+\mathrm{CO}$ reached its maximum value (78\%). Hence, it is clear that, when applying all the parameters in Table 3 to the present model, the optimum conditions for
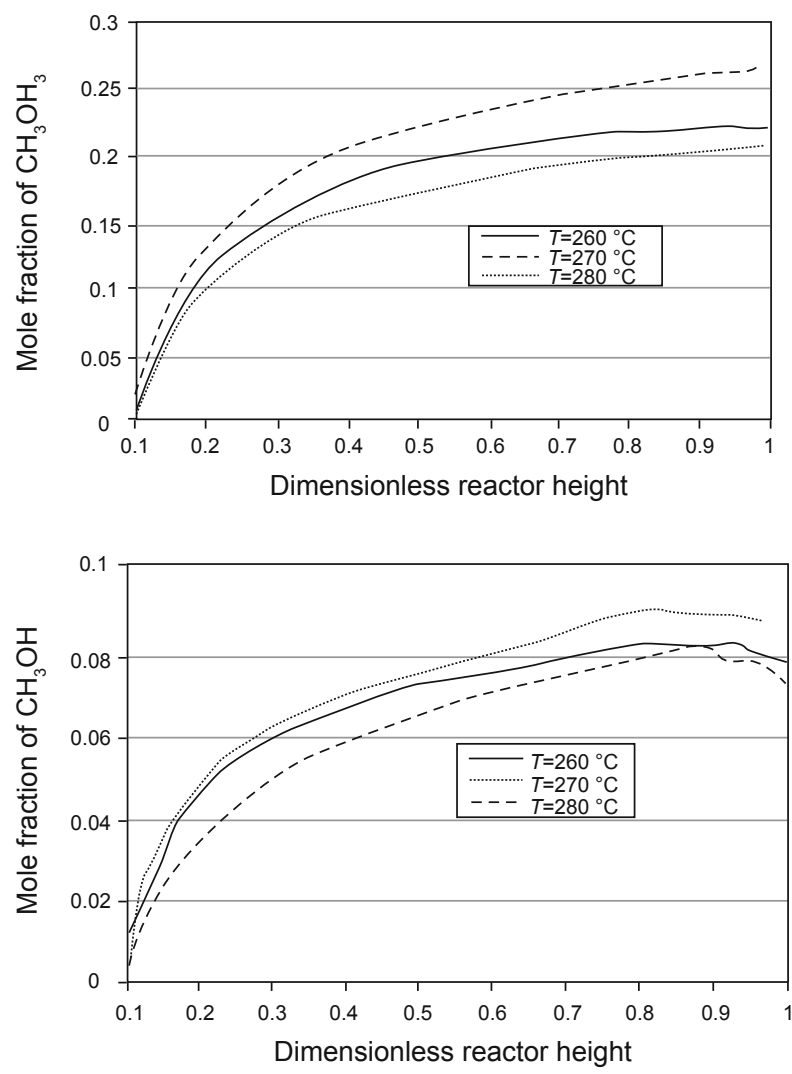

Fig. 5 Effect of temperature on mole fractions of the DME and methanol along the reactor height



Fig. 6 Effect of temperature on optimum reactor height

the process are 5.0 MPa and $270{ }^{\circ} \mathrm{C}$. The simulated fixed bed results were compared with those of the commercial slurry reactor employing the same dimensions and operating conditions in Table 3. Fig. 8 shows the comparison of the syngas $\left(\mathrm{H}_{2}+\mathrm{CO}\right)$ conversion for these two reactors. It can be
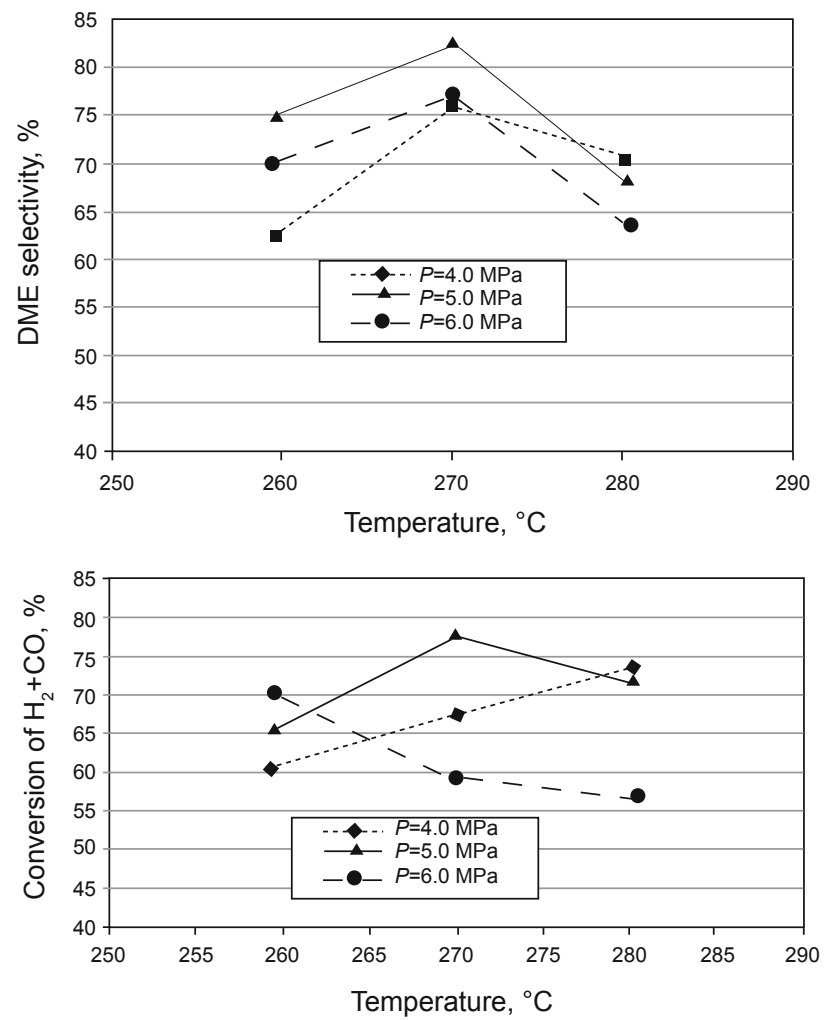

Fig. 7 DME selectivity and conversion of syngas versus temperature in an adiabatic fixed bed reactor

seen that the results obtained from these two reactors agree well with each other. However, the conversion of $\mathrm{H}_{2}+\mathrm{CO}$ in the fixed bed in this work was slightly higher than that in the slurry reactor. This confirmed that the mass transfer resistance, caused by the diffusion due to increased reactor's dimensions for the fixed bed reactor, can be negligible.

The boundary conditions for a fixed bed reactor were changed from adiabatic to isothermal and the system's behavior was simulated once again. The comparison of the obtained results for these two scenarios (adiabatic and isothermal) under commercial scale is displayed in Fig. 9.

Through implementing the operating conditions in Table 3 , the results of the $\mathrm{H}_{2}+\mathrm{CO}$ conversion versus temperature in Fig. 9 revealed that the conversion of $\mathrm{H}_{2}+\mathrm{CO}$ in the isothermal fixed bed reactor was greater than that in the adiabatic fixed bed at all the temperatures studied. Moreover, the highest $\mathrm{H}_{2}+\mathrm{CO}$ conversion in the isothermal reactor was determined at $260{ }^{\circ} \mathrm{C}$. In addition, at interval of 255 $265{ }^{\circ} \mathrm{C}$ the difference of $\mathrm{H}_{2}+\mathrm{CO}$ conversion between these two reactors was considerable nonetheless, at $270{ }^{\circ} \mathrm{C}$ this difference was rather negligible, because at temperatures beyond $260{ }^{\circ} \mathrm{C}$, the $\mathrm{H}_{2}+\mathrm{CO}$ conversion in the isothermal fixed bed reactor decreased with increasing temperature but in an adiabatic fixed bed reactor this decrease occurred beyond $270{ }^{\circ} \mathrm{C}$. Therefore, the effect of the exothermic nature of reactions appeared earlier in an isothermal fixed bed reactor than in adiabatic fixed bed reactor. On the other hand, in order to simultaneously consider the effects of temperature and 


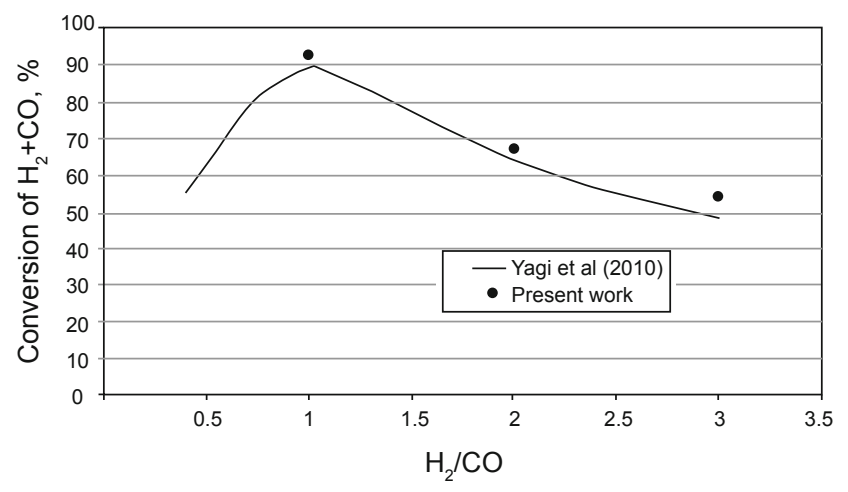

Fig. 8 Comparison of the syngas conversion vs. the $\mathrm{H}_{2} / \mathrm{CO}$ ratio

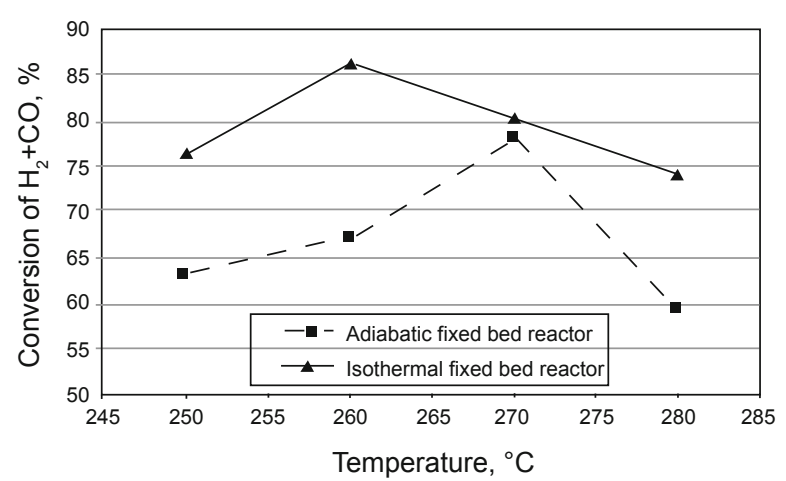

Fig. 9 Conversion of $\mathrm{H}_{2}+\mathrm{CO}$ vs. temperature in the adiabatic and isothermal fixed bed reactors

pressure on the $\mathrm{H}_{2}+\mathrm{CO}$ conversion and DME selectivity in the isothermal fixed bed reactor, simulations were performed for temperatures of $250,260,270$ and $280{ }^{\circ} \mathrm{C}$ at three pressures of 4.0, 5.0 and 6.0 MPa under the same operating conditions in Table 3. These results are displayed in Fig. 10.

Fig. 10 shows that the maximum $\mathrm{H}_{2}+\mathrm{CO}$ conversion (86\%) appeared at $5.0 \mathrm{MPa}$ and $260^{\circ} \mathrm{C}$ in the isothermal fixed bed reactor. At higher temperatures (e.g., $270{ }^{\circ} \mathrm{C}$ ) the conversion variations with pressure (e.g., 4.0 MPa) were more pronounced. Moreover, at $4.0 \mathrm{MPa}$, the $\mathrm{H}_{2}+\mathrm{CO}$ conversion changed uniformly than that at other two pressures and the maximum conversion $(83 \%)$ was obtained at $270{ }^{\circ} \mathrm{C}$ rather than at $260{ }^{\circ} \mathrm{C}$ for the higher pressures. Consequently, when the pressure was lower, the effect of the exothermic nature of reactions appeared with a delay. In other words, under such pressures, the maximum conversion was achieved at a higher temperature. At $6.0 \mathrm{MPa}$, the $\mathrm{H}_{2}+\mathrm{CO}$ conversion had the lowest value compared with those at 4.0 and 5.0 MPa. The DME selectivity in the isothermal fixed bed reactor had the similar changes to that in adiabatic fixed bed reactor, and the maximum DME selectivity $(83 \%)$ appeared at $270{ }^{\circ} \mathrm{C}$ and 5.0 MPa. At $260{ }^{\circ} \mathrm{C}$ and $5.0 \mathrm{MPa}$, the DME selectivity reached $81 \%$. Considering the selectivity and conversion, the optimal pressure for synthesis of DME was determined to be $5.0 \mathrm{MPa}$, while the optimal temperature to be $270{ }^{\circ} \mathrm{C}$ based on the selectivity criterion, and to be $260{ }^{\circ} \mathrm{C}$ based on the conversion criterion. In other words, the simultaneous comparison of conversion and selectivity at 260 and $270{ }^{\circ} \mathrm{C}$ showed that, the optimum temperature was $260{ }^{\circ} \mathrm{C}$ because
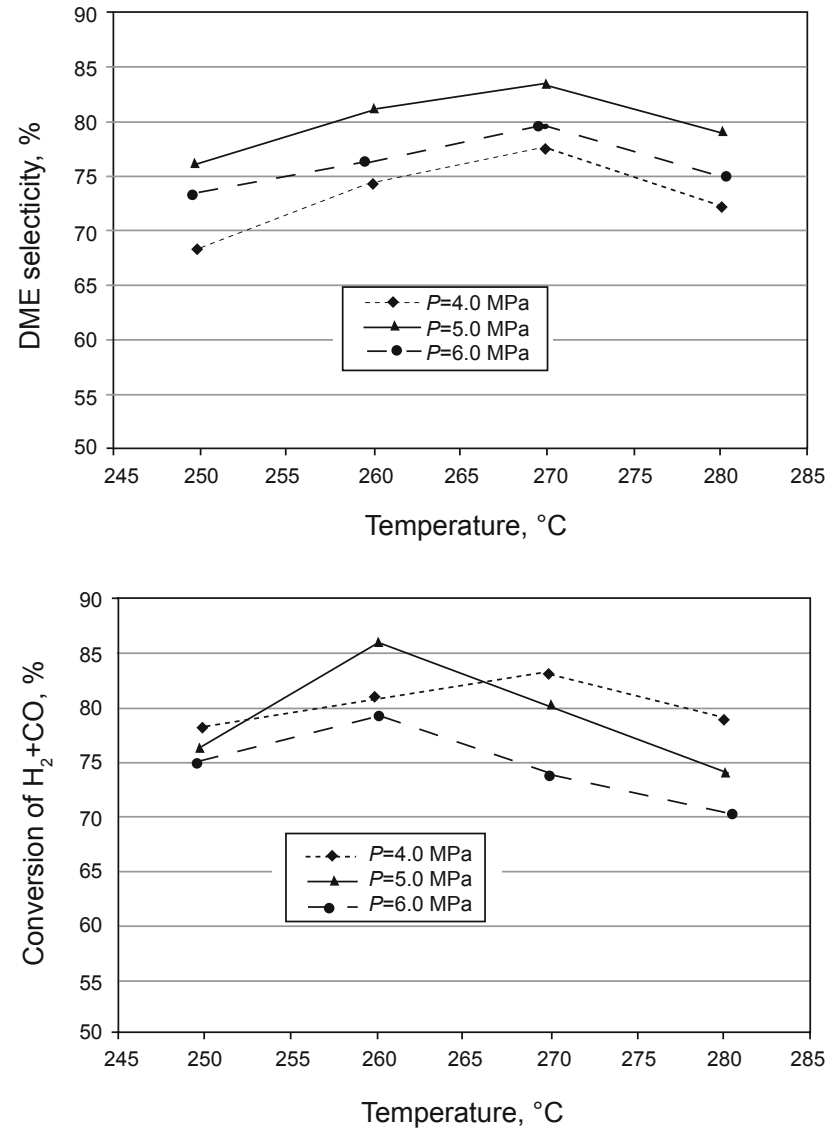

Fig. 10 DME selectivity and conversion of syngas versus temperature in the isothermal fixed bed reactor

the DME selectivity at these two temperatures was close to each other, while the conversion at $260{ }^{\circ} \mathrm{C}$ was considerably higher than that at $270{ }^{\circ} \mathrm{C}$.

\section{Conclusions}

In this study, production of the DME in a fixed-bed reactor was modeled. The simulation of this fixed bed reactor was done by ANSYS FLUENT. The effects of variations of temperature and pressure for adiabatic as well as isothermal fixed bed reactor modes were studied and the obtained results were compared with an adiabatic slurry bed reactor at a commercial scale. The best ratio of $\mathrm{CO}$ to $\mathrm{H}_{2}$ for the entering feed was determined to be unity because the conversion maximized at this ratio. 5.0 $\mathrm{MPa}$ was found to be the optimum pressure for both adiabatic and isothermal operating modes. Under adiabatic conditions at $270{ }^{\circ} \mathrm{C}$ and $5.0 \mathrm{MPa}$ the maximum selectivity of $82.1 \%$ obtained. The optimum temperature and pressure for simulated adiabatic fixed bed reactor revealed to be $270{ }^{\circ} \mathrm{C}$ and $5.0 \mathrm{MPa}$, respectively. The optimum reactor height defined as the one at which the methanol production runaway rate reached zero. At the optimum pressure of $5.0 \mathrm{MPa}$ and temperatures of 260,270 and $280{ }^{\circ} \mathrm{C}$ optimum heights of 42,46 and $48 \mathrm{~m}$ respectively were determined. Consequently, the optimum height was $42 \mathrm{~m}$ at $260{ }^{\circ} \mathrm{C}$ and $5.0 \mathrm{MPa}$. Ultimately, by changing the condition of the reactor from adiabatic to isothermal, for the isothermal fixed bed reactor the maximum conversion of $\mathrm{CO}+\mathrm{H}_{2}$ was $86.2 \%$ at $260{ }^{\circ} \mathrm{C}$ and $5.0 \mathrm{MPa}$. 
Increasing pressure beyond 5.0 $\mathrm{MPa}$ reduced conversion at all temperatures. The maximum value of selectivity determined was about $81 \%$ and occurred at $270{ }^{\circ} \mathrm{C}$ and $5.0 \mathrm{MPa}$. Hence, the optimum pressure through considering both selectivity and conversion was 5.0 MPa. Moreover, the selectivity at 260 ${ }^{\circ} \mathrm{C}$ and $5.0 \mathrm{MPa}$ was determined to be $81.2 \%$ and conversion at $270{ }^{\circ} \mathrm{C}$ and $5.0 \mathrm{MPa}$ reached $80.3 \%$. Furthermore, due to a low difference of selectivities between 260 and $270{ }^{\circ} \mathrm{C}$ and superiority of conversion at $260{ }^{\circ} \mathrm{C}$ with respect to that at the $270{ }^{\circ} \mathrm{C}$, the optimum temperature was concluded to be at $260{ }^{\circ} \mathrm{C}$. Finally, the optimum pressure for both adiabatic and isothermal operating modes determined to be at 5.0 MPa while the temperatures were rationalized to be 260 and 270 ${ }^{\circ} \mathrm{C}$, respectively. Ultimately it is noteworthy that the novelties of the present simulation were a thorough 3-D CFD modeling of the process as well as including effects of the temperature variations.

\section{Appendix A}

The $\mathrm{CO}$ and $\mathrm{H}_{2}$ conversion (\%) were calculated from the following formulae:

$$
\begin{aligned}
& \text { CO conversion }(\%)=\frac{\text { Mole of } \mathrm{CO}_{\text {in }}-\text { Mole of } \mathrm{CO}_{\text {out }}}{\text { Mole of } \mathrm{CO}_{\text {in }}} \times 100 \\
& \mathrm{H}_{2} \text { conversion }(\%)=\frac{\text { Mole of } \mathrm{H}_{2_{\text {in }}}-\text { Mole of } \mathrm{H}_{2_{\text {out }}}}{\text { Mole of } \mathrm{H}_{2_{\text {in }}}} \times 100
\end{aligned}
$$

The selectivity (\%) towards the DME synthesis on $\mathrm{CO}+\mathrm{H}_{2}$ basis is calculated according to:

\section{Selectivity of DME (\%)}

$$
=\frac{\text { Mole of DME Product }}{\text { Mole of }\left(\mathrm{H}_{2}+\mathrm{CO}\right)_{\text {in }}-\text { Mole of }\left(\mathrm{H}_{2}+\mathrm{CO}\right)_{\text {out }}} \times 100
$$

\section{References}

Alamolhoda S, Kazemeini M, Zaherian A, et al. Reaction kinetics determination and neural networks modeling of methanol dehydration over nano $\gamma-\mathrm{Al}_{2} \mathrm{O}_{3}$ catalyst. Journal of Industrial and Engineering Chemistry. 2012. 18(6): 2059-2068

Arkharov A M, Glukhov S D, Grekhov L V, et al. Use of dimethyl ether as a motor fuel and a refrigerant. Chemical and Petroleum Engineering. 2003. 39(5-6): 330-336

Farsi $\mathrm{M}$ and Jahanmiri A. Enhancement of DME production in an optimized membrane isothermal fixed-bed reactor. International
Journal of Chemical Reactor Engineering. 2011. 9: A74

Jahanmiri A and Eslamloueyan R. Optimal temperature profile in methanol synthesis reactor. Chemical Engineering Communications. 2002. 189(6): 713-741

Khandan N, Kazemeini M and Aghaziarati M. Determining an optimum catalyst for liquid-phase dehydration of methanol to dimethyl ether. Applied Catalysis A: General. 2008. 349(1-2): 6-12

Lim H W, Park M J, Kang S H, et al. Modeling of the kinetics for methanol synthesis using $\mathrm{Cu} / \mathrm{ZnO} / \mathrm{Al}_{2} \mathrm{O}_{3} / \mathrm{ZrO}_{2}$ catalyst: Influence of carbon dioxide during hydrogenation. Industrial and Engineering Chemistry Research. 2009. 48(23): 10448-10455

Moradi G R, Ghanei R, Yaripour F. Determination of the optimum operating conditions for direct synthesis of dimethyl ether from syngas. International Journal of Chemical Reactor Engineering. 2007. 5: A14

Ng K L, Chadwick D and Toseland B A. Kinetics and modelling of dimethyl ether synthesis from synthesis gas. Chemical Engineering Science. 1999. 54(15-16): 3587-3592

Ogawa T, Ono M, Okuyama K, et al. Direct dimethyl ether synthesis from hydrogen and carbon monoxide. NKK Technical Review. 1999. 81: 13-17

Papari S, Kazemeini M and Fattahi M. Modelling-based optimisation of the direct synthesis of dimethyl ether from syngas in a commercial slurry reactor. Chinese Journal of Chemical Engineering. 2013. 21(6): 611-621

Papari S, Kazemeini M and Fattahi, M. Mathematical modeling of a slurry reactor for DME direct synthesis from syngas. Journal of Natural Gas Chemistry. 2012. 21(2): 148-157

Shahrokhi M and Baghmisheh G R. Modeling, simulation and control of a methanol synthesis fixed-bed reactor. Chemical Engineering Science. 2005. 60(15): 4275-4286

Takeguchi T, Yanagisawa K-i, Inui T, et al. Effect of the property of solid acid upon syngas-to-dimethyl ether conversion on the hybrid catalysts composed of $\mathrm{Cu}-\mathrm{Zn}-\mathrm{Ga}$ and solid acids. Applied Catalysis A: General. 2000. 192(2): 201-209

Topsoe H., Process for the preparation of catalysts for use in ether synthesis. 1993a. US Patent 4,536,485

Topsoe H., Process for preparing acetic acid, methyl acetate, acetic anhydride or mixtures thereof. 1993b. US Patent 5,189,203

Yagi H, Ohno Y, Inoue N, et al. Slurry phase reactor technology for DME direct synthesis. International Journal of Chemical Reactor Engineering. 2010. 8: A109

Yaripour F, Baghaei F, Schmidt I, et al. Catalytic dehydration of methanol to dimethyl ether (DME) over solid-acid catalysts. Catalysis Communications. 2005. 6(2):147-152

Yasari E, Shahrokhi M and Abedini H. Modeling, simulation and control of a tubular fixed-bed dimethyl ether reactor. Chemical and Biochemical Engineering Quarterly. 2010. 24(4): 415-423

(Edited by Zhu Xiuqin) 